\title{
Evaluation and Association Mapping of Resistance to Tan Spot and Stagonospora Nodorum Blotch in Adapted Winter Wheat Germplasm
}

\begin{abstract}
Zhaohui Liu, Department of Plant Pathology, North Dakota State University, Fargo 58102; Ibrahim El-Basyoni, Department of Agronomy and Horticulture, University of Nebraska, Lincoln 68583; Gayan Kariyawasam, Department of Plant Pathology, North Dakota State University, Fargo; Guorong Zhang, Agricultural Research Center-Hays, Kansas State University, Hays 67601; Allan Fritz, Department of Agronomy, Kansas State University, Manhattan 66506; Jana Hansen, Department of Plant Pathology, North Dakota State University, Fargo; Francois Marais, Department of Plant Science, North Dakota State University, Fargo; Andrew Friskop, Department of Plant Pathology, North Dakota State University, Fargo; Shiaoman Chao, United States Department of Agriculture-Agricultural Research Service, Biosciences Research Laboratory, Fargo, ND, 58105; Eduard Akhunov, Department of Plant Pathology, Kansas State University Manhattan; and P. Stephen Baenziger, Department of Agronomy and Horticulture, University of Nebraska, Lincoln
\end{abstract}

\begin{abstract}
Liu, Z., El-Basyoni, I., Kariyawasam, G., Zhang, G., Fritz, A., Hansen, J., Marais, F., Friskop, A., Chao, S., Akhunov, E., and Baenziger, P. S. 2015. Evaluation and association mapping of resistance to tan spot and Stagonospora nodorum blotch in adapted winter wheat germplasm. Plant Dis. 99:1333-1341

Tan spot and Stagonospora nodorum blotch (SNB), often occurring together, are two economically significant diseases of wheat in the Northern Great Plains of the United States. They are caused by the fungi Pyrenophora tritici-repentis and Parastagonospora nodorum, respectively, both of which produce multiple necrotrophic effectors (NE) to cause disease. In this work, 120 hard red winter wheat (HRWW) cultivars or elite lines, mostly from the United States, were evaluated in the greenhouse for their reactions to the two diseases as well as NE produced by the two pathogens. One P. nodorum isolate (Sn4) and four Pyrenophora tritici-repentis isolates (Pti2, 331-9, DW5, and AR CrossB10) were used separately in the disease evaluations. NE sensitivity evaluation included ToxA, Ptr ToxB, SnTox1, and SnTox3. The numbers of lines that were

rated highly resistant to individual isolates ranged from $11(9 \%)$ to 30 (25\%) but only six lines (5\%) were highly resistant to all isolates, indicating limited sources of resistance to both diseases in the U.S. adapted HRWW germplasm. Sensitivity to ToxA was identified in $83(69 \%)$ of the lines and significantly correlated with disease caused by $\mathrm{Sn} 4$ and Pti2, whereas sensitivity to other NE was present at much lower frequency and had no significant association with disease. As expected, association mapping located ToxA and SnTox 3 sensitivity to chromosome arm 5BL and 5BS, respectively. A total of 24 potential quantitative trait loci was identified with $-\log (P$ value $)>3.0$ on 12 chromosomes, some of which are novel. This work provides valuable information and tools for HRWW production and breeding in the Northern Great Plains.
\end{abstract}

Tan spot and Stagonospora nodorum blotch (SNB), caused by Pyrenophora tritici-repentis (anamorph: Drechslera tritici-repentis), and Parastagonospora nodorum (synonym Stagonospora nodorum, teleomorph: Phaeosphaeria nodorum), respectively, are two of the most common and important diseases of wheat (Triticum spp.) in the northern Great Plains of the United States (De Wolf et al. 1998; McMullen and Adhikari 2009; Singh et al. 2006). The two diseases often occur simultaneously and are major components of the leaf spotting complex (McMullen and Adhikari 2009). The typical symptoms of tan spot are tan, elliptical lesions with a distinctive yellow border, while SNB results in lens-shaped necrotic lesions without an obvious halo. However, the two diseases are not easily distinguishable from each other in the late growing season when the lesions coalesce. Both diseases can cause significant yield losses of up to $50 \%$ if highly susceptible cultivars are used and conditions are favorable for disease development (Bhathal et al. 2003; Karjalainen et al. 1983; Shabeer and Bockus 1988). Additionally, grain quality can be adversely affected by tan spot and SNB, which could lead to the formation of red smudge and shriveled kernels, respectively (King et al. 1983; Schilder and Bergstrom 1990).

Unlike rust disease, resistance to tan spot and SNB often appears to be polygenic and environmentally dependent (De Wolf et al. 1998;

Corresponding author: Z. Liu; E-mail: zhh.liu @ndsu.edu

*The $\boldsymbol{e}$-Xtra logo stands for "electronic extra" and indicates that one supplementary table is published online.

Accepted for publication 12 March 2015

http://dx.doi.org/10.1094/PDIS-11-14-1131-RE

(C) 2015 The American Phytopathological Society
$\mathrm{Xu}$ et al. 2004a). Lack of major resistance genes and a poor understanding of the nature of resistance have made breeding for SNB or tan spot resistance a major challenge. However, during the last several decades, great progress has been made in the understanding of the genetic and molecular basis of these two diseases. It is now known that both disease systems involve the interactions of necrotrophic effectors (NE; previously known as host-selective toxins) produced by the fungal pathogens and corresponding host sensitivity genes (Faris et al. 2013; Oliver et al. 2012). They have been described as inverse gene-for-gene systems as opposed to a classic gene-for-gene model because the NE-host sensitivity gene interaction leads to susceptibility or disease rather than resistance (Ciuffetti et al. 2010; Faris et al. 2013; Friesen et al. 2007). Because multiple toxin-host gene interactions are present in each population and they are mainly additive, reaction to these pathogens is often characterized as quantitative (Friesen and Faris 2010). From a breeding point of view, sensitivity genes should be removed from breeding materials to obtain a high level of resistance (Faris et al. 2013).

Three NE (Ptr ToxA, Ptr ToxB, and Ptr ToxC) have been identified and characterized from Pyrenophora tritici-repentis and each interacts with its corresponding host gene ( $T s n 1, T s c 2$, and $T s c 1$, respectively) to produce tan spot disease symptoms, including necrosis (Ptr ToxA) or chlorosis (Ptr ToxB and Ptr ToxC) (Ciuffetti et al. 2010). P. tritici-repentis isolates have been classified into eight races based on their virulence phenotypes on a set of differential lines, which is basically determined by the NE they produce (Faris et al. 2013). In the SNB system, six pairs of NE-host gene have been identified, including SnTox1-Snn1, SnToxA-Tsn1, SnTox2-Snn2, SnTox3-Snn3-5B/Snn3-5D, SnTox4Snn4, and SnTox5-Snn5 (Friesen et al. 2012; Oliver et al. 2012). Interestingly, both fungal pathogens produce ToxA, which interacts with the same host gene, Tsn1. Study has strongly suggested that the ToxAencoding gene (ToxA) was horizontally transferred from Parastagonospora nodorum to Pyrenophora tritici-repentis (Friesen et al. 2006). 
Screening for resistance to tan spot or SNB has been conducted on various wheat germplasms, including bread wheat from Brazil (Rees and Platz 1990); synthetic hexaploid wheat (Xu et al. 2004b); tetraploid wheat, including Triticum turgidum, T. carthlicum, T. dicoccum, T. polonicum, and T. dicoccoides (Chu et al. 2008a,c); hard red spring wheat cultivars or elite breeding lines from the Northern Great Plains (Mergoum et al. 2007; Singh et al. 2006); and wild grass-wheat derivatives (Alam and Gustapson 1988; Oliver et al. 2008). This has led to the identification of some sources of resistance to each disease or both. Recently, Noriel et al. (2011) evaluated a collection of worldwide winter wheat germplasm for resistance to tan spot (race 1) and sensitivity to ToxA. It was found that most accessions were resistant and there was a weak correlation between tan spot score and ToxA sensitivity. Although the study included 212 accessions from the United States, most of them were breeding lines. The hard red winter wheat (HRWW) cultivars from the United States have not been systematically evaluated against multiple races of two pathogens. Additionally, the disease role of the NE in HRWW genetic backgrounds needs to be further investigated.

Genetic mapping has been conducted to locate quantitative trait loci (QTL) associated with resistance to tan spot and SNB using either biparental or natural populations. For tan spot, some QTL mapped to the same loci as NE sensitivity genes, including Tsn1 (5BL), Tsc2 (2BS), and Tsc1 (1AS), indicating the important role of these NE. However, in many cases, tan spot resistance QTL were identified to genomic regions different from the three NE sensitivity loci (Faris et al. 2013; Kollers et al. 2014; Patel et al. 2013). Different from tan spot resistance, the majority of identified SNB resistance QTL were colocalized to loci conferring sensitivity to NE, indicating that all Parastagonospora nodorum NE play an important role in disease development (Friesen et al. 2012; Oliver et al. 2012). Among the previous studies, most were done using spring wheat genotypes, and only a few were done with HRWW germplasm.

In this work, we evaluated 120 HRWW lines, mainly the cultivars from the central and northern Great Plains, for their reactions to multiple Pyrenophora tritici-repentis races and one $P$. nodorum isolate as well as the NE produced by the two pathogens. The hypothesis is that these HRWW genotypes significantly differ in their reactions to the two fungal pathogens and the NE the fungi produced. The objectives were to determine the levels of tan spot and SNB resistance or susceptibility in this set of adapted HRWW germplasm and to understand the disease role of different NE in HRWW genetic backgrounds. In addition, association mapping was utilized to identify genomic regions associated with resistance or susceptibility to tan spot and SNB.

\section{Materials and Methods}

Plant materials. In total,120 entries, including 95 commercially available HRWW cultivars and 25 elite HRWW breeding lines, were evaluated in the greenhouse at the seedling stage for their reactions to tan spot and SNB as well as NE produced by the two pathogens (Supplementary Table S1). Among them, 54 lines were primarily developed by the University of Nebraska, Lincoln and 44 lines were primarily developed by Kansas State University, Manhattan. The remaining 22 entries were selected from the 2012-13 North Dakota Winter Wheat Variety Trial (Ransom et al. 2013), including cultivars from the public breeding programs in North Dakota, South Dakota, Montana, and Canada as well as private sectors (WestBred and Agripro-Syngenta). The cultivar collections from both Nebraska and Kansas included lines released from the 1950s to the present. Salamouni, Glenlea, 6B365, and 6B662 were included as a differential set for tan spot screening and BR34 and Grandin as the resistant and susceptible checks for SNB evaluation.

Plant preparations. The evaluation for all the entries was done at the seedling stage under controlled greenhouse and growth chamber conditions. To prepare for planting, supercell Cone-tainers (Stuewe and Sons, Inc.) were placed in RL98 racks and filled with Sunshine SB100 soil (Sun Gro Horticulture). Each cone-tainer was sown with three seeds of an individual line followed by an application of Osmocote Plus 15-19-12 fertilizer (Scotts Sierra Horticultural Product Company). Each entry was planted in two cones in each of three experiments. The plants were arranged with a randomized complete block design. Susceptible 'Grandin' was planted in the cones around the borders on each RL 98 rack to reduce the edge effect. Plants were grown in a greenhouse with temperatures of 20 to $25^{\circ} \mathrm{C}$ and an $18-\mathrm{h}$ photoperiod until the two- to three-leaf stage, when they were used for spore inoculation and NE infiltration.

Evaluation of reaction to $P$. tritici-repentis. Four $P$. tritici-repentis isolates were used, including Pti2, DW5, 331-9 (Friesen et al. 2005), and AR CrossB10 (Ali et al. 2010), representing races 1, 3, 5, and a newly identified race, respectively. The evaluation was conducted individually with each isolate. Preparation of fungal cultures and inoculum and fungal inoculations were done as described by Friesen et al. (2003). The fungus was cultured on V8-potato dextrose agar (PDA) in the dark for 5 days at room temperature. The fungal colony was then flooded with sterilized distilled water and all aerial mycelium was flattened to the surface of the medium with the bottom of a flamed test tube. After the water was discarded, the plate was incubated under fluorescent light for $24 \mathrm{~h}$ at room temperature followed by a 24-h incubation in the dark at $16^{\circ} \mathrm{C}$. The conidia were harvested by washing the plate with sterilized water and the spore concentration was adjusted to $3,000 \mathrm{ml}^{-1}$. Surfactant agent Tween 20 was added to the spore suspension at two drops per $100 \mathrm{ml}$ before inoculation. The inoculum was applied to the leaf surface using a paint sprayer (Husky; Home Depot) attached to an air supply with an air pressure setting around 1.0 bar. The plants were sprayed until small water drops uniformly covered the leaf. Right after the inoculation, the plants were moved to a misting chamber with $100 \%$ relative humidity for $24 \mathrm{~h}$. The plants were then moved to the growth chamber with the temperature at $21^{\circ} \mathrm{C}$ and humidity at approximately $75 \%$. At 7 days after inoculation, the disease was rated on a 1-to-5 scale, as described by Lamari and Bernier (1989), which is based on the lesion type shown on the secondary leaf. In this scale, lesion types of 1 and 2 were considered resistant, 3.0 a moderately resistant to moderately susceptible reaction, 4.0 moderately susceptible, and 5.0 a highly susceptible reaction (Lamari and Bernier 1989). For each line, the most common lesion type from all plants in two cone-tainers was recorded as a reading. The readings from three independent inoculation experiments were used to calculate the average and in the subsequent statistical analysis.

Evaluation of reaction to Parastagonospora nodorum. The single isolate Sn4, which was collected in Langdon, ND and found to produce all known Parastagonospora nodorum NE (Chu et al. 2008a), was used for evaluation. The fungus culturing and inoculum preparation followed the descriptions by Liu et al. (2004b). The fungus was grown on V8-PDA plates for 5 to 7 days until the majority of pycnidia were releasing spores. The spores were harvested by adding approximately $10 \mathrm{ml}$ of sterilized water and scraping the plate surface with an inoculation loop. The obtained spore suspension solution was checked for concentration, which was then adjusted to $1 \times 10^{6} \mathrm{ml}^{-1}$. The spore suspension was inoculated as described above until water ran off the leaf surface. Misting and incubation conditions postinoculation were the same as described for tan spot screening. Disease reaction was rated at 7 days after inoculation using a lesion-based 0-to-5 scale (Chu et al. 2008a; Liu et al. 2004b).

Evaluation of reaction to NE. The four NE genes ToxA, ToxB, SnToxl, and SnTox3 have been cloned from the two fungal pathogens and heterologously expressed in the Pichia pastoris yeast strain x33 (Abeysekara et al. 2010; Liu et al. 2009, 2012). The yeast strains expressing individual NE genes were grown in yeast potato dextrose broth (Liu et al. 2012) for 24 to $48 \mathrm{~h}$ at $30^{\circ} \mathrm{C}$ with agitated shaking. The culture was then spun down to collect the supernatant for infiltration. Infiltrations were performed as described by Liu et al. (2004a). Briefly, approximately $20 \mu \mathrm{l}$ of culture filtrate was infiltrated into leaf tissue by using a needleless 1-ml syringe, and the water-soaked expansion area was marked. The NE reaction was rated 3 days after infiltration using a 0 -to-3 scale, with 0 having no reaction, 1 having weak necrosis, 2 having intermediate necrosis, and 3 having strong necrosis (Friesen and Faris 2012).

Statistical analysis. Data from three independent experiments were used in statistical analysis and the average was used to show the reaction to different isolates. Testing of the difference in reactions to each isolate among lines was conducted using the one-way 
analysis of variance and measured by Fisher's protected least significant difference. Regression analysis was performed to test for significant correlations between sensitivity to $\mathrm{NE}$ and disease reactions. To compare the difference of the mean from NE-sensitive lines and insensitive lines, the one-way Student's $t$ test was performed. All tests and analyses were done using the Statistical Analysis System 9.30 (SAS Institute 2010). Due to the low frequency of SnTox1 and Ptr ToxB sensitivity, no statistical test was done for the comparison of disease means.

Association mapping. As part of the Triticeae Coordinated Agricultural Project, the wheat cultivars and breeding lines selected by the project participants have been genotyped using the wheat iSelect single-nucleotide polymorphism (SNP) array containing 90,000 SNP (Wang et al. 2014). The genotypic data were deposited and made available to the project members in the project database, The Triticeae Toolbox (http://triticeaetoolbox.org/wheat/). Among the 120 lines evaluated for disease reactions, only 70 have SNP marker data available (verified 18 June 2014). Therefore, association mapping was done on only 70 lines that have both phenotypic and genotypic data. Before performing the association tests, markers with allele frequencies $<0.05$ and missing values more than $10 \%$ were removed. The association analysis was carried out by using the PC-based software rrBLUPpackage in R (Endelman 2011). A linear mixed model with restricted maximum likelihood estimates (Kang et al. 2008) was used for association analysis, including both structure and kinship in the model. The model is expressed as: $Y=\mu+Q v+Z u+W m+e$, where $Y$ is a vector of phenotypic observation, $\mu$ is a vector of intercepts, $v$ is a $k \times 1$ vector of population effects, $u$ is an $n \times 1$ vector of random polygene background effects, $e$ is a vector of random experimental errors with a mean of 0 and covariance matrix $\operatorname{Var}(e), Q$ is an $n \times 1$ vector defining the time of the experiment, and $Z$ is an incidence matrix relating $y$ to $u$. $\operatorname{Var}(u)=$ $2 K V g$, where $K$ is a known $n \times n$ matrix of kinship coefficients, $V g$ is the unknown genetic variance which is a scalar, $m$ is a vector of fixed effect due to the SNP markers effect, and $W$ is an incidence matrix relating $Y$ to $m$. $\operatorname{Var}(e)=R V R$, where $R$ is an $n \times n$ matrix and $V R$ is the unknown residual variance.

\section{Results}

A wide range of variation was observed in this set of $120 \mathrm{HRWW}$ germplasms for their reactions to all five fungal isolates. The average reaction types for individual lines ranged from 0.5 to 4.5 for $\mathrm{Sn} 4,1.0$ to 4.8 for Pti2, 1.0 to 4.5 for $331-9,1.0$ to 4.3 for DW5, and 1.3 to 5 for AR CrossB10 (Fig. 1). Significant differences $(P<0.001)$ in lesion types were observed among the lines for each pathogen isolate. The distribution of all lines in each category of lesion type is shown in
Figure 1. The largest number (from 51 to 61 ) of the lines fell into the category of 3.1 to 4.0 , indicating that they were susceptible to all the isolates. Small numbers (from 4 to 22) of the lines had disease scores greater than 4.1 exhibiting a highly susceptible reaction. The numbers of lines having average lesion types between 2.1 and 3.0 were from 19 to 35 for each isolate, indicating that these lines had an intermediate reaction. Of the 120 lines evaluated, $26(21.7 \%), 11(9.2 \%), 18$ (15\%), $30(25 \%)$, and $22(18.3 \%)$ had average disease ratings lower than or equal to 2.0 for Sn4, Pti2, 331-9, DW5, and AR CrossB10, respectively, which indicates high levels of resistance to each isolate. Among them, only six lines, including 'Colt', 'Wesley', 'Freeman', 'SY Wolf', 'Betty', and 'Ron L', were highly resistant to all five isolates. The levels of resistance in these lines were comparable with the resistant differential line Salamouni for tan spot and resistant check BR34 for Sn4 (Table 1; Figs. 2 and 3). Four lines-NE06607 (Nebraska breeding line), 'Hawken', 'Decade', and KS12HW32 (Kansas breeding line)—were also highly resistant to most isolates but were moderately resistant (score $\leq 2.5$ ) to one of the five pathogen isolates (Table 1).

Among the 95 commercially available HRWW cultivars, 67 (70\%), 74 (77\%), 68 (71\%), $62(65 \%)$, and $74(77 \%)$ were rated from moderately susceptible to susceptible to Sn4, Pti2, 331-9, DW5, and AR CrossB10, respectively. The top two cultivars in term of acreage in Nebraska in 2012 and 2013, 'Settler_CL' and 'Overland', had moderately resistant reactions to most fungal isolates. However, several cultivars that are currently planted in a large area in North Dakota and Kansas, including 'Jerry', 'CDC Falcon', 'Everest', 'Danby', and 'Fuller', were susceptible to most fungal isolates (Table 1). In addition to Jerry and CDC Falcon, another 12 lines were found to be highly susceptible to all four isolates, including 'Arapahoe', 'Centura', 'Goodstreak', 'Hallam', 'Harry', 'McGill', 'Norkan', 'Redland', 'Robidoux', 'Parker', 'Parker76', and Nord1301 (a North Dakota State University breeding line) (Table 1). These lines developed large, necrotic lesions or a chlorotic border to all five isolates (Figs. 2 and 3).

Of the 120 lines evaluated, $83(69.2 \%)$ were sensitive to ToxA, with all developing strong necrosis and having a reading of 3.0. For reaction to SnTox3, 42 (35\%) were sensitive, with 29 showing strong necrosis, 8 showing intermediate necrosis, and 5 showing weak necrosis. Only 18 and 6 lines showed weak reactions to Ptr ToxB and SnTox1, respectively. Sensitivity to ToxA was significantly correlated with disease caused by Sn4 $(r=0.52, P<$ $0.00001)$ and Pti2 $(r=0.27, P=0.00119)$, both of which are known to produce ToxA as a virulence factor. As expected, sensitivity to ToxA had no significant correlation with the other three isolates,

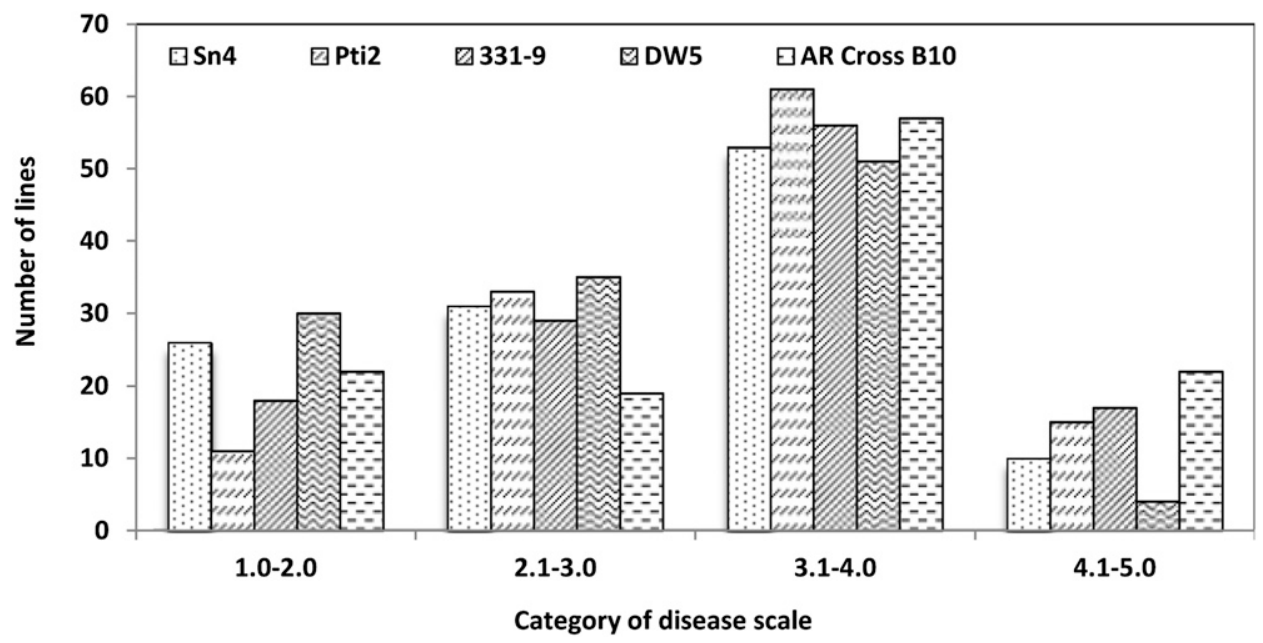

Fig. 1. Number of 120 hard red winter wheat (HRWW) lines in each category of disease scale based on their reactions to each isolate of Pyrenophora tritici-repentis and Parastagonospora nodorum. Evaluations included one P. nodorum isolate (Sn4) and four Pyrenophora tritici-repentis isolates (Pti2, 331-9, DW5, and AR CrossB10), indicated by columns with different formats of filling. The Y-axis is the number of HRWW lines and the X-axis is disease scale used in the evaluation. The disease scales have a range from 1.0 to 5.0 , with 1.0 being highly resistant and 5.0 being highly susceptible for the two diseases. 
including 331-9, DW5, and AR CrossB10, that do not produce ToxA (Table 2). We also compared the disease mean of ToxA-insensitive (ToxA-) and ToxA-sensitive (ToxA+) lines for the reaction to Sn4 and Pti2. For Sn4 inoculation, the mean disease scores for ToxAand ToxA+ were 2.2 and 3.3, respectively, and the scores were significantly different $(P<0.05)$. Among the 37 insensitive lines, only 16 had disease lesion type higher than 2.5 , while the majority of sensitive lines (74 of 86) had disease lesion types greater than 2.5. Similarly, the mean disease scores of ToxA- and ToxA+ lines to Pti2 were also significantly different $(2.8$ versus $3.3, P<0.05$;

Table 1. Seedling reactions of individual hard red winter wheat genotypes to fungal inoculations with four Pyrenophora tritici-repentis races and one Parastagonospora nodorum isolate, as well as their reactions to infiltration with four necrotrophic effectors (NE) produced by the two fungal pathogens

\begin{tabular}{|c|c|c|c|c|c|c|c|c|c|c|c|c|}
\hline \multirow[b]{2}{*}{ Variety, lines } & \multirow[b]{2}{*}{ Yearc $^{c}$} & \multirow{2}{*}{$\begin{array}{l}\text { Breeding } \\
\text { programs }\end{array}$} & \multirow[b]{2}{*}{ Pedigree/crosses } & \multicolumn{5}{|c|}{ Reaction to fungus ${ }^{a}$} & \multicolumn{4}{|c|}{ Reaction to $\mathrm{NE}^{\mathrm{b}}$} \\
\hline & & & & Sn4 & Pti2 & $331-9$ & DW5 & $\mathbf{A R}$ & $\mathbf{A}$ & B & 1 & 3 \\
\hline Colt & 1983 & NE/ARS & $\begin{array}{l}\text { Agate sib (NE69441)//391-56-D8/Kaw } \\
\text { (Tx65A1503-1) }\end{array}$ & 1.5 & 1.3 & 2.0 & 1.5 & 1.7 & 0 & 0 & 0 & 3 \\
\hline Wesley & 2000 & NE/SD/WY & $\begin{array}{l}\text { KS831936-3/NE86501 [Sumner sib } \\
\text { (Plainsman V/Odesskaya 51)//Colt/Cody] }\end{array}$ & 2.0 & 1.3 & 2.0 & 1.5 & 1.7 & 0 & 0 & 0 & 0 \\
\hline Freeman & 2014 & NE/ARS & $\begin{array}{l}\text { KS92-946-B-15-1 } \\
\text { (ABI86*3414/Jagger/Kar192)/Alliance }\end{array}$ & 1.3 & 1.8 & 1.8 & 2.0 & 1.8 & 0 & 0 & 0 & 2 \\
\hline SY Wolf & 2010 & APS & W99-331/97 × 0906-8 & 1.8 & 0.8 & 1 & 1.3 & 1.5 & 0 & 0 & 0 & 0 \\
\hline Ron L & 2005 & KS & TREGO/CO960293 & 1.2 & 2.0 & 1.8 & 1.3 & 2 & 3 & 0 & 0 & 0 \\
\hline Betty & 1998 & KS & JAGGER HW SEL (KS82W418/Stephens) & 0.8 & 1 & 1.3 & 1.3 & 1.2 & 0 & 0 & 0 & 0 \\
\hline NE06607 & $\ldots$ & $\mathrm{NE}$ & $\mathrm{NE} 98466=($ KS89H50-4/NE905189 $=\mathrm{BR})$ & 2.2 & 2.3 & 2.2 & 2.3 & 1.8 & 3 & 0 & 0 & 0 \\
\hline Hawken & 2006 & APS & Heyne/Tomahawk//Thunderbird/Hickok & 1.0 & 1.7 & 2.5 & 1.7 & 1.3 & 3 & 0 & 0 & 0 \\
\hline Decade & 2010 & $\mathrm{MT} / \mathrm{ND}$ & $\begin{array}{l}\text { From three F1 (N95L159/CDC Clair, } \\
\text { N95L159/MT9602, and } \\
\text { N95L159/MT9609) }\end{array}$ & 1.0 & 1.3 & 2.5 & 1.8 & 1.7 & 0 & 0 & 0 & 0 \\
\hline KS12HW32 & $\ldots$ & $\mathrm{KS}$ & $\begin{array}{l}\text { KS03HW6-6CL/OSU3049 } \\
\text { (ATTILA/2*PASTOR)//RonL }\end{array}$ & 1.8 & 2.5 & 2 & 1.8 & 2 & 3 & 1 & 0 & 3 \\
\hline Overland & 2007 & SD/NE/ARS & Millennium sib//Seward/Archer & 2.8 & 2.8 & 1.3 & 2.8 & 2.3 & 3 & 0 & 0 & 0 \\
\hline Settler_CL & 2008 & NE/SD/WY & 'Wesley’ sib//'Millennium’ sib/‘Above’ sib & 1.8 & 2.2 & 1.8 & 2.8 & 2.5 & 3 & 0 & 0 & 0 \\
\hline Everest & 2009 & KS & HBK1064-3/JAGGERW//X960103 & 0.5 & 2.8 & 3.3 & 2 & 3.2 & 0 & 0 & 0 & 2 \\
\hline Danby & 2004 & KS & TREGO/JGR 8W & 3 & 3.7 & 3.3 & 3 & 4.2 & 3 & 1 & 0 & 0 \\
\hline Jerry & 2000 & ND & Roughrider'/ND7571//‘Arapahoe’ & 3.8 & 4.2 & 4.2 & 4 & 4.5 & 3 & 0 & 0 & 2 \\
\hline CDC Falcon & 1998 & $\mathrm{CDC}$ & Norstar*2/Vona//Abilene & 3.8 & 3.5 & 4.3 & 3.3 & 3.7 & 3 & 0 & 0 & 3 \\
\hline McGill & 2010 & $\mathrm{NE}$ & NE92458 (OK83201/Redland)/IKe & 3.2 & 4.3 & 4.3 & 3.8 & 3.8 & 3 & 0 & 0 & 0 \\
\hline Parker & 1966 & KS & $\begin{array}{l}\text { Quivara/3/Kanred/Hard } \\
\text { Federatin//Prelude/Kanred/4/Kawwvale/ } \\
\text { Marquillo//Kawvale/Tenmarq }\end{array}$ & 4.2 & 3.8 & 4 & 3.7 & 4.8 & 3 & 0 & 0 & 0 \\
\hline Arapahoe & 1988 & $\mathrm{NE}$ & $\begin{array}{l}\text { Brule/3/Parker *4/Agent//Beloterkovskaja } \\
\text { 198/Lancer }\end{array}$ & 4.2 & 3.8 & 3.8 & 3.7 & 4.2 & 3 & 0 & 0 & 0 \\
\hline Centura & 1983 & $\mathrm{NE}$ & Warrior $* 5 /$ Agent/NE68457/3/Centurk 78 & 3.5 & 4.2 & 4.2 & 4 & 4.2 & 3 & 0 & 0 & 3 \\
\hline Goodstreak & 2002 & NE/WY & D3055/KS88H164//NE89646 & 3.7 & 4.3 & 4.2 & 4 & 3.7 & 3 & 0 & 0 & 0 \\
\hline Hallam & 2004 & $\mathrm{NE}$ & Brule/Bennett//Niobrara & 4 & 4.5 & 4.5 & 4.2 & 4 & 3 & 0 & 0 & 1 \\
\hline Harry & 2002 & NE & $\begin{array}{l}\text { NE90614 (Brule/4/Parker } \\
\text { *4/Agent//Beloterkovskaia } \\
\text { 198/Lancer/3/Newton/Brule)/NE87612 } \\
\text { (Newton//Warrior *5/Agent/3/Agate sib.) }\end{array}$ & 4 & 4.5 & 4.5 & 4.3 & 4.2 & 3 & 0 & 0 & 1 \\
\hline Redland & 1989 & $\mathrm{NE}$ & Selection from Brule & 4.3 & 4.3 & 4.3 & 4.2 & 3.7 & 3 & 0 & 0 & 0 \\
\hline Robidoux & 2010 & $\mathrm{NE}$ & $\begin{array}{l}\text { NE96644(Odesskaya P/Cody//Pavon } \\
\text { 76/3*Scout 66')/Wahoo }\end{array}$ & 3.7 & 4 & 4.5 & 3.7 & 3.7 & 3 & 0 & 0 & 0 \\
\hline Nord1301 & $\ldots$ & ND & Arapahoe/Danby & 3.7 & 4.2 & 4.3 & 3.8 & 4.3 & 3 & 0 & 0 & 0 \\
\hline Norkan & 1985 & KS & PLAINSMAN V/2/KS76H3705 & 3.5 & 4.2 & 3.8 & 3.7 & 4.8 & 3 & 0 & 0 & 0 \\
\hline Parker76 & 1976 & KS & Parker $* 5 /$ Agent & 4.2 & 4 & 4 & 3.5 & 5 & 3 & 0 & 0 & 0 \\
\hline Salamouni & $\ldots$ & $\ldots$ & Differential lines for tan spot & $\ldots$ & 1 & 1.0 & 1.1 & 1.0 & 0 & 0 & 1 & 0 \\
\hline Glenlea & $\ldots$ & $\ldots$ & Differential lines for tan spot & $\ldots$ & 4 & 3 & 2.5 & 3.5 & 3 & 0 & 0 & 2 \\
\hline $6 \mathrm{~B} 662$ & $\ldots$ & $\ldots$ & Differential lines for tan spot & $\ldots$ & 2.7 & 2.5 & 3.6 & 2.3 & 0 & 1 & 0 & 0 \\
\hline $6 \mathrm{~B} 365$ & $\ldots$ & $\ldots$ & Differential lines for tan spot & $\ldots$ & 4.3 & 4.5 & 2.1 & 4.3 & 0 & 0 & 0 & 0 \\
\hline BR34 & $\cdots$ & $\cdots$ & Resistant check for SNB & 1 & 1.2 & 1.0 & 1.2 & 1.3 & 0 & 0 & 0 & 0 \\
\hline Grandin & $\ldots$ & $\ldots$ & Susceptible check for SNB & 4.3 & 3.7 & 4.3 & 3.1 & 3.5 & 3 & 0 & 1 & 1 \\
\hline $\mathrm{LSD}^{\mathrm{e}}$ & $\ldots$ & $\ldots$ & $\ldots$ & 0.47 & 0.38 & 0.36 & 0.42 & 0.51 & $\ldots$ & $\ldots$ & $\ldots$ & \\
\hline
\end{tabular}

a Evaluation of disease reaction was based on a 1-to-5 scale for tan spot as described by Lamari and Bernier (1989) and a 0-to-5 scale for Stagonospora nodorum blotch (SNB) as described by Liu et al. (2004b) (see Materials and Methods). The average reading of three replications was used to show the disease reaction for each line. Four isolates representing different races of Pyrenophora tritici-repentis-Pti2 (race 1), 331-9 (race 3), DW5 (race 5), and AR (AR CrossB10, new race) - were used for tan spot inoculations and one isolate, Sn4, collected in North Dakota, was used for SNB inoculation.

b NE evaluations included ToxA (A), Ptr ToxB (B), SnTox1 (1), and SnTox3 (3). The evaluation of NE reactions was based on the 0-to-3 scale developed by Friesen and Faris (2012).

c Year indicates the time when the particular cultivar was released. Lines indicated by-were still breeding lines from the individual breeding programs at the time of evaluation.

d NE, ND, KS, SD, MT, and WY indicate the states of Nebraska, North Dakota, Kansas, South Dakota, Montana, and Wyoming, respectively, where a particular breeding program is located. ARS = Agricultural Research Service of the United States Department of Agriculture; CDC = Crop Development Centre, University of Saskatchewan; and APS = Agripro-Syngenta, a private breeding company.

e Least significant difference. 
Table 3). However, there was no significant correlation between NE sensitivity and disease reaction for SnTox3, SnTox1, and Ptr ToxB with the isolates that are known to produce them (Table 2). The disease means of SnTox3- and SnTox3+ for the reaction to $\mathrm{Sn} 4$ were also shown not significantly different at $P<$ 0.05 using a $t$ test (Table 3 ).

As expected, sensitivity to ToxA mapped to chromosome 5BL at 280.68 centimorgans $(\mathrm{cM})$ with $-\log _{10}(P$ value $)$ of 22 , which corresponds to the Tsn1 locus (Table 4). Sensitivity to SnTox3 also mapped to the expected chromosomal location at the position of 1.33 $\mathrm{cM}$ on 5BS with $-\log _{10}(P$ value $)$ of 8.5 . In total, 24 putative QTL were identified with $-\log _{10}(P$ value $)>3.0$ for the five isolates: 4 for $\mathrm{Sn} 4,5$ for Pti2, 7 for 331-9, 4 for DW5, and 4 for AR CrossB10 (Table 4). The proportion of variation explained by these QTL ranged from 0.02 to 0.10 (Table 4). Several markers on 5BL associated with reaction to ToxA were also associated with the disease reaction to Sn4. Other QTL for Sn4 were identified on chromosome 5B at $188.5 \mathrm{cM}$, 5A at $415.88 \mathrm{cM}$, and 5D at $61.48 \mathrm{cM}$. For Pti2, QTL were distributed on five genomic regions on four chromosomes, including 2D $(372.57 \mathrm{cM}), 4 \mathrm{~A}$ (497.16 cM and 540.69 cM), 5D (178.51 cM), and 7A (284.0 to 289.2 cM). Seven genomic regions on chromosome $2 \mathrm{~A}$ (394.36 and 453.86 $\mathrm{cM}), 3 \mathrm{~B}$ (349.56 and $490 \mathrm{cM}), 3 \mathrm{D}(0 \mathrm{cM}), 4 \mathrm{~A}(191.56 \mathrm{cM})$, and 7A $(312.62 \mathrm{cM})$ were identified as having markers associated with reaction to 331-9. For isolate DW5, there were four genomic regions on chromosomes 3B (423.69 cM), 5D (173.31 cM), 6B $(299.54 \mathrm{cM})$, and 7B $(261.14 \mathrm{cM})$ identified. For the new race AR CrossB 10, regions on chromosome 2A (394.36 cM), 4A (191.56 $\mathrm{cM}), 6 \mathrm{~A}(158.77 \mathrm{cM})$, and $6 \mathrm{~B}(385.1 \mathrm{cM})$ were identified. Two regions, one on $2 \mathrm{~A}(394.36 \mathrm{cM})$ and the other on $4 \mathrm{~A}(191.56$ cM), had QTL for both 331-9 and AR CrossB10.

\section{Discussion}

Using resistant cultivars is the most economical and sustainable way to reduce the impact of tan spot and SNB on wheat production in the northern Great Plains. Screening wheat germplasm to identify sources of resistance for both diseases is essential for long-term disease management. In this study, 120 adapted HRWW germplasm were evaluated for resistance to the two diseases using multiple races or isolates that are currently present in North America. From this evaluation, we identified six lines that were highly resistant to both diseases and all isolates tested, which could serve as sources of resistance for diverse breeding programs. Additionally, we obtained detailed information on the level of susceptibility for each cultivar or experimental line.

Previous studies for identifying sources of resistance were done for one (Mergoum et al. 2007; Noriel et al. 2011; Rees and Platz 1990; Singh et al. 2006) or both of these diseases but only with one or two races or isolates (Ali et al. 2008; Chu et al. 2008a,c; Xu et al. 2004b). Because we evaluated these lines with multiple races or isolates of the two pathogens, it was possible to provide a comprehensive and robust data set to wheat breeders. For example, 'Karl 92' was reported to be highly resistant to Pyrenophora tritici-repentis race 1 and has been used as a source of resistance for tan spot resistance breeding (Noriel et al. 2011). We confirmed that the cultivar is highly resistant to the race 1 isolate Pti2; however, it is moderately susceptible to the new race AR CrossB10 and to Parastagonospora nodorum isolate $\mathrm{Sn} 4$. Therefore, Karl 92 might not be the ideal resistance source for breeding programs.

A large portion of the HRWW lines evaluated were susceptible to individual isolates, which is similar to the findings from most of the previous studies using other wheat germplasm (Ali et al. 2008; Chu et al. 2008a,c; Mergoum et al. 2007; Singh et al. 2006; Xu et al. 2004b). Noriel et al. (2011) conducted the first tan spot resistance screening in a collection of winter wheat germplasm including cultivars, breeding lines, and landraces mainly from the United States and China. The authors found that $60 \%$ of the accessions were resistant compared with the resistant check Karl 92 but, among 25 U.S. winter wheat cultivars evaluated in that study, only 4 were rated as resistant. Those results indicated that resistance to the two diseases is limited, particularly in the U.S. adapted HRWW germplasm.
Major HRWW cultivars in North Dakota, Nebraska, and Kansas, such as Jerry, CDC Falcon, Danby, and Fuller (Table 1), were included in our evaluation and were shown to be susceptible. Jerry has been the leading winter wheat cultivar in North Dakota for more than 10 years (United States Department of Agriculture National Agricultural Statistics Service; http://www.nass.usda.gov/). Our data showed that Jerry was among the genotypes that are most susceptible to all of the isolates (Figs. 2 and 3). It is imperative to improve tan spot and SNB resistance in these cultivars to reduce potential yield losses caused by these two diseases. Wesley (Nebraska) and SY Wolf (AgriPro-Syngenta) were highly resistant to all pathogen isolates (Figs. 2 and 3) and both have shown some adaption in North Dakota. The broad-spectrum resistance in these two cultivars can be employed by breeding programs in North Dakota to improve the level of resistance in new widely adapted cultivars. Decade and Hawken, which have been planted in North Dakota, have high levels of resistance to all isolates except race 3 isolate 331-9. The expanding use of two cultivars is recommended to reduce the risk of yield loss due to tan spot and SNB because race 3 has not been detected in North Dakota (Ali and Francl 2003). The most popular cultivars in Kansas and Nebraska are Everest and Settler_CL, respectively, which had intermediate or susceptible reactions to one or two races. Breeding efforts should aim to improve the level of resistance to these races.

In this study, $69 \%$ of the lines evaluated were sensitive to ToxA and sensitivity was significantly associated with the diseases caused by Pti2 and Sn4, which indicates that genotypes sensitive to ToxA were likely susceptible to the two isolates. With the exception of Ron L, the six highly resistant cultivars were insensitive to ToxA. This indicates that ToxA plays an important role in diseases caused by these two isolates for this set of HRWW germplasm. Noriel et al. (2011) reported that approximately $40 \%$ of the lines were sensitive to ToxA in a worldwide collection of winter wheat accessions but they also detected a weak correlation of ToxA sensitivity with tan spot disease caused by a race 1 isolate. Therefore, removing ToxA sensitivity in HRWW cultivars would likely lead to less susceptibility to tan spot.

Many lines were insensitive to ToxA but were still highly susceptible to Pyrenophora tritici-repentis race 1; for example, 'Millennium', 'Camelot', and 'Stanton'. ToxA-insensitive and tan spot-susceptible lines have also been identified in the previous screening studies (Ali et al. 2008; Noriel et al. 2011; Singh et al. 2006). This could be explained by the presence of Ptr ToxC or other unknown NE-sensitivity gene interactions (Faris et al. 2013; Noriel et al. 2011). Conversely, Ron L was sensitive to ToxA but was highly resistant to $P$. tritici-repentis race 1. This type of resistant line was also identified by Noriel et al. (2011) at a very low frequency. We speculate that those lines may have a resistance

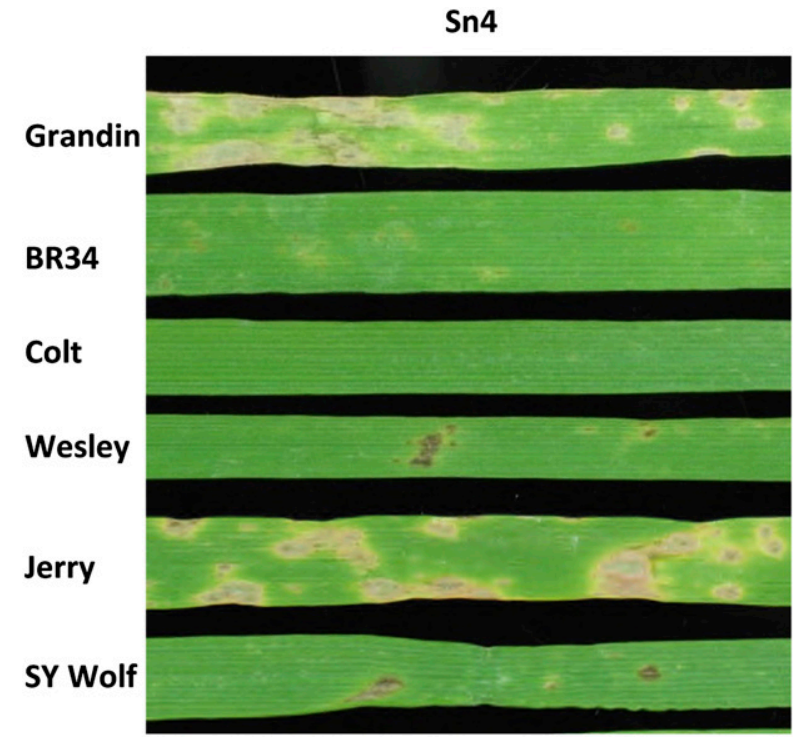

Fig. 2. Reactions of the resistant and susceptible checks, three highly resistant lines, and one highly susceptible line to Parastagonospora nodorum isolate Sn4. BR34 and Grandin are resistant and susceptible checks, respectively. 
mechanism that acts in the early infection stage prior to the occurrence of compatible reactions of ToxA-Tsn1. Ron L and the other five highly resistant cultivars could also carry broad-spectrum, race-nonspecific resistance to tan spot, as described by Faris and Friesen (2005), because they were resistant to all four races. In the tan spot system, it has been recognized that the host-pathogen relationship is complicated, not merely based on the three known NE-sensitivity gene interactions, and research is needed to characterize these unknown pathogen virulence and host resistance factors (Faris et al. 2013).
The wheat-Parastagonospora nodorum system has been shown to be largely based on the NE-host sensitivity gene interactions that act in an inverse gene-for-gene manner (Friesen and Faris 2010). In this set of germplasm, sensitivity to ToxA was significantly correlated with disease caused by $\mathrm{Sn} 4$, indicating that the ToxA-Tsnl interaction is very important in disease development of SNB. However, we did not observe a significant association between sensitivity to SnTox3 and SNB. Currently, six NE have been identified and characterized from $P$. nodorum and the importance of each NE in SNB development has been shown to
A

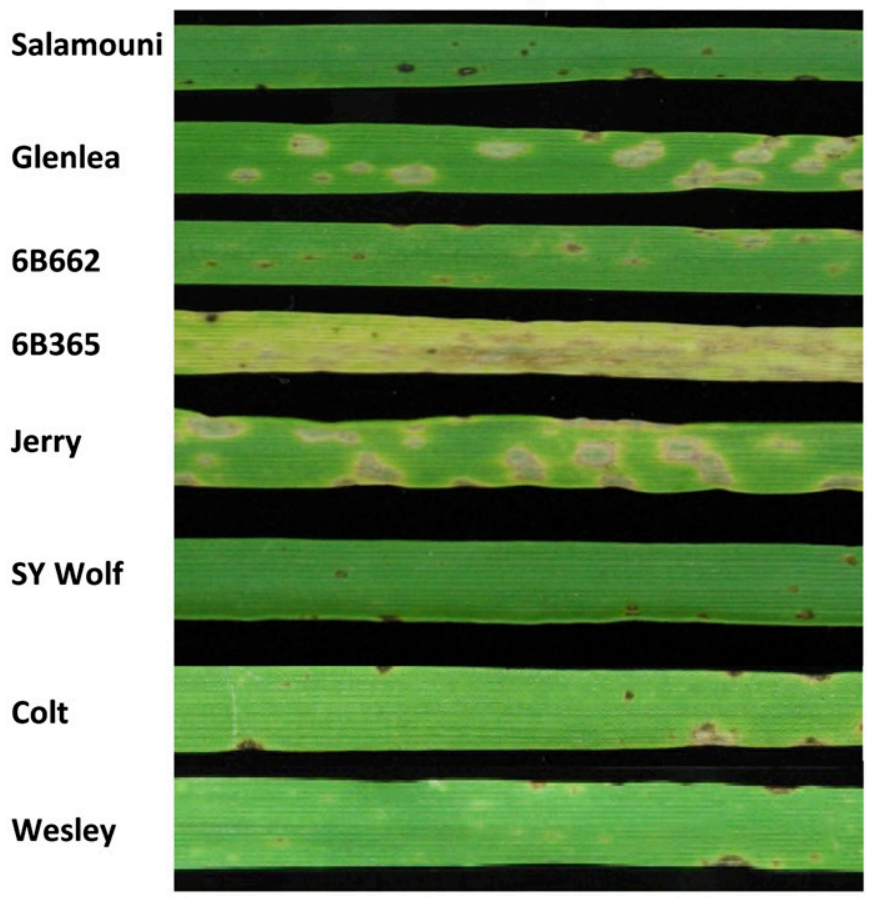

C

Salamouni

Glenlea

$6 B 662$

$6 B 365$

Jerry

SY Wolf

Colt

Wesley
B

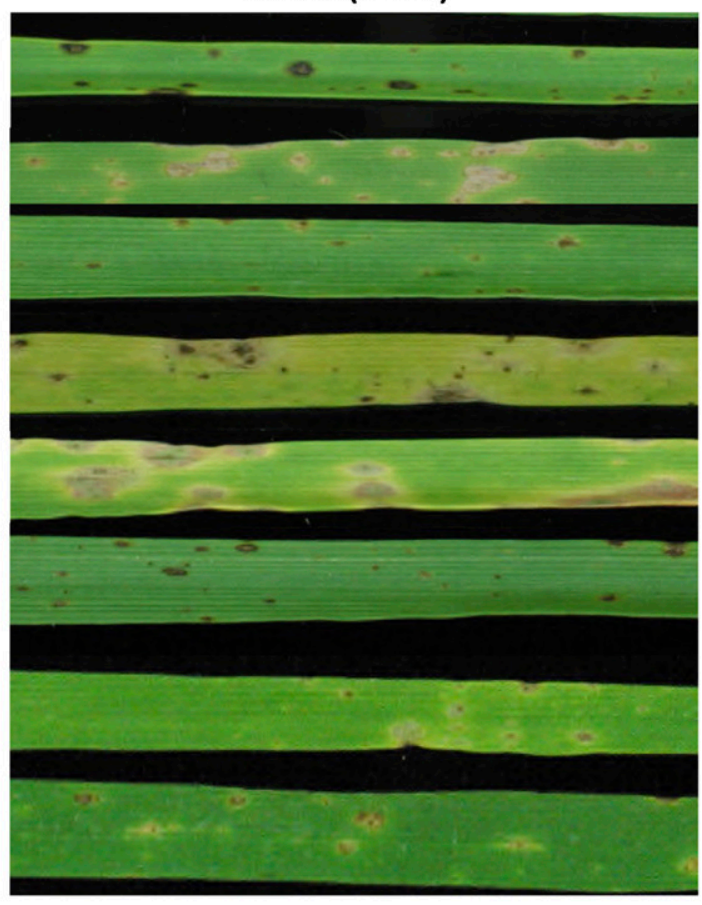

D

AR CrossB10

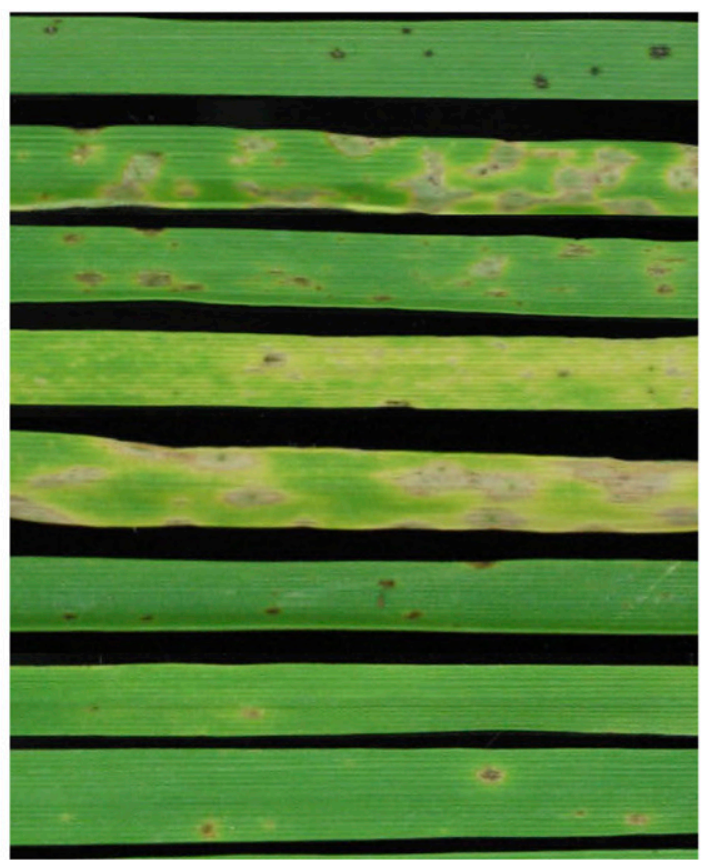

Fig. 3. Reactions of tan spot differential lines, three highly resistant lines, and one highly susceptible line to each of Pyrenophora tritici-repentis isolates A, Pti2; B, 331-9; C, DW5; and $\mathbf{D}$, AR CrossB10. The isolates Pti2, 331-9, and DW5 represented the three known races of $P$. tritici-repentis: race 1, 3, and 5 respectively; AR CrossB10 is a new race identified by Ali et al. (2010). Salamouni is a universal resistant line for all the races. Glenlea, 6B662, and 6B365 are the susceptible differentials for the races producing Ptr ToxA (race 1 ), Ptr ToxB (race 5), and Ptr ToxC (race 1, 3, and the new race), respectively. 
be dependent on the genetic backgrounds of the pathogen and the host (Friesen and Faris 2010). The role of SnTox 3 in disease has ranged from being $100 \%$ correlated (Zhang et al. 2011) to weakly associated (Friesen et al. 2007; Liu et al. 2009) to no association due to the presence of other

Table 2. Correlation between the reactions to necrotrophic effectors (NE) and disease reactions caused by isolates of Pyrenophora tritici-repentis and Parastagonospora nodorum in hard red winter wheat (HRWW) lines

\begin{tabular}{lccccc}
\hline Isolates, NE & Sn4 & Pti2 & $\mathbf{3 3 1 - 9}$ & DW5 & AR Cross B10 \\
\hline ToxA & $0.520^{* * *}$ & $0.270^{* *}$ & $0.007^{\mathrm{NS}}$ & $0.140^{\mathrm{NS}}$ & $0.022^{\mathrm{NS}}$ \\
Ptr Tox B & $\ldots$ & $\ldots$ & $\ldots$ & $0.11^{\mathrm{NS}}$ & $\ldots$ \\
Sn Tox1 & $0.090^{\mathrm{NS}}$ & $\ldots$ & $\ldots$ & $\ldots$ & $\ldots$ \\
Sn Tox3 & $-0.130^{\mathrm{NS}}$ & $\ldots$ & $\ldots$ & $\ldots$ & $\ldots$
\end{tabular}

${ }^{a}$ HRWW lines were evaluated with five isolates, including Sn4 for Stagonospora nodorum blotch; Pti2, 331-9, DW5, and AR CrossB10 for tan spot; and four NE, including ToxA, Ptr ToxB, SnTox1, and SnTox3. Significance level was indicated by NS (nonsignificant), ** (significant at $P<0.01$ ), *** (significant at $P<0.001$ ), or $\ldots$ (no calculation was done for the two traits). major NE-sensitivity gene interactions such as Sn ToxA-Tsnl or SnTox2-Snn2 (Friesen et al. 2008). In this case, it is most likely that the SnTox3-Snn3 interaction was masked by the ToxA-Tsn1 interaction.

Association mapping was conducted on a total of 70 lines whose SNP markers and phenotypic data are both available. The size of the population for association mapping was relatively small but we were able to locate sensitivity to ToxA and SnTox 3 to the previously known chromosomal locations with a high significance level $\left(-\log _{10}[P\right.$ value $]=22$ and 8.6, respectively), indicating that this subset of winter wheat material is suitable for association mapping. Furthermore, we identified 24 QTL with $-\log _{10}(P$ value $)>3.0$ for resistance to the disease caused by the five isolates. Tommasini et al. (2007) reported the detection of a major SNB resistance QTL on 3BS using an association mapping approach with only 44 European winter wheat cultivars.

Several studies have been done to map resistance to the two diseases using the association mapping approach (Adhikari et al. 2011; Gurung et al. 2011; Kollers et al. 2014; Patel et al. 2013; Tommasini et al. 2007). Because different marker types (simple sequence repeat or diversity arrays technology) have been used, it is difficult to compare

Table 3. Two-sample $t$ tests to compare the differences of average reactions to fungal isolates according to reactions to necrotrophic effector (NE) ToxA or SnTox3

\begin{tabular}{|c|c|c|c|c|c|c|}
\hline Isolate & NE reaction ${ }^{a}$ & Mean & Standard deviation & Standard error & $t$ & $P$ \\
\hline \multirow[t]{2}{*}{$\mathrm{Sn} 4$} & ToxA- & 2.2 & 0.9 & 0.14 & 6.70 & $<0.00001$ \\
\hline & ToxA+ & 3.3 & 0.8 & 0.08 & $\ldots$ & $\ldots$ \\
\hline \multirow[t]{2}{*}{$\operatorname{Sn} 4$} & SnTox3- & 3.0 & 0.9 & 0.10 & 1.40 & 0.09 \\
\hline & SnTox3+ & 2.8 & 1.01 & 0.16 & $\ldots$ & $\ldots$ \\
\hline \multirow[t]{2}{*}{ Pti2 } & ToxA- & 2.8 & 0.96 & 0.15 & 3.12 & 0.001129 \\
\hline & ToxA+ & 3.3 & 0.68 & 0.07 & $\ldots$ & $\ldots$ \\
\hline
\end{tabular}

${ }^{\text {a }}$ NE reaction was scored using a 0-to-3 scale developed by Friesen and Faris (2012), with 0 being no reaction, 1 being the development of weak necrosis, 2 being the development of intermediate necrosis, and 3 being the development of strong necrosis. Reaction of 0 was classified as insensitive (-) and reactions of 1,2 , and 3 were classified as sensitive (+).

Table 4. Association mapping detection of quantitative trait loci significantly associated with resistance to disease caused by Pyrenophora tritici-repentis and Parastagonospora nodorum as well as with sensitivity to necrotrophic effectors (NE) produced by the two pathogens in a collection of hard red winter wheat cultivars

\begin{tabular}{|c|c|c|c|c|c|}
\hline Isolates, NE & Markera & Chromosome $^{b}$ & Position $^{b}$ & $-\log (P$ value $)$ & $R^{2 \mathrm{c}}$ \\
\hline ToxA & IWB36366 & $5 \mathrm{~B}$ & 280.68 & 22.7 & 0.15 \\
\hline SnTox3 & IWB7864 & $5 \mathrm{~B}$ & 1.33 & 8.5 & 0.06 \\
\hline \multirow[t]{4}{*}{$\mathrm{Sn} 4$} & IWB67424 & $5 \mathrm{~A}$ & 415.88 & 6.4 & 0.10 \\
\hline & IWB36366 & $5 \mathrm{~B}$ & 280.68 & 6.4 & 0.10 \\
\hline & IWB38178 & $5 \mathrm{~B}$ & 188.5 & 3.6 & 0.06 \\
\hline & IWB45668 & $5 \mathrm{D}$ & 61.48 & 3.3 & 0.06 \\
\hline \multirow[t]{5}{*}{ Pti2 } & IWB20112 & $2 \mathrm{D}$ & 372.57 & 3.4 & 0.06 \\
\hline & IWB11339 & $4 \mathrm{~A}$ & 540.69 & 3.4 & 0.06 \\
\hline & IWB47813 & $4 \mathrm{~A}$ & 497.16 & 3.4 & 0.06 \\
\hline & IWB45442 & $5 \mathrm{D}$ & 178.51 & 3.1 & 0.05 \\
\hline & IWB68544 & $7 \mathrm{~A}$ & 284.85 & 3.3 & 0.06 \\
\hline \multirow[t]{7}{*}{$331-9$} & IWB64643 & $2 \mathrm{~A}$ & 394.36 & 3.5 & 0.06 \\
\hline & IWB74851 & $2 \mathrm{~A}$ & 453.86 & 3.1 & 0.05 \\
\hline & IWB9575 & 3B & 490 & 4.0 & 0.07 \\
\hline & IWB51094 & $3 \mathrm{~B}$ & 349.56 & 3.1 & 0.05 \\
\hline & IWB64735 & $3 \mathrm{D}$ & 0 & 3.3 & 0.06 \\
\hline & IWB35182 & $4 \mathrm{~A}$ & 191.56 & 3.3 & 0.07 \\
\hline & IWB51002 & $7 \mathrm{~A}$ & 312.62 & 3.6 & 0.06 \\
\hline \multirow[t]{4}{*}{ DW5 } & IWB64607 & $3 \mathrm{~B}$ & 428.55 & 3.3 & 0.05 \\
\hline & IWB6788 & $5 \mathrm{D}$ & 179.66 & 4.2 & 0.08 \\
\hline & IWB70366 & $6 \mathrm{~B}$ & 299.54 & 3.1 & 0.02 \\
\hline & IWB45141 & $7 \mathrm{~B}$ & 261.14 & 3.1 & 0.02 \\
\hline \multirow[t]{4}{*}{ AR CrossB10 } & IWB64643 & $2 \mathrm{~A}$ & 394.36 & 4.2 & 0.06 \\
\hline & IWB35182 & $4 \mathrm{~A}$ & 191.56 & 3.9 & 0.05 \\
\hline & IWB3978 & $6 \mathrm{~A}$ & 158.77 & 4.5 & 0.09 \\
\hline & IWB62163 & $6 \mathrm{~B}$ & 385.1 & 3.4 & 0.06 \\
\hline
\end{tabular}

a Single-nucleotide polymorphism (SNP) marker data were downloaded from the T3 wheat database (http://triticeaetoolbox.org/wheat) (verified 18 June 2014).

$\mathrm{b}$ Information on the chromosomes and positions of all SNP markers was also obtained from the Triticeae Coordinated Agricultural Project website.

${ }^{\mathrm{c}} R^{2}$ is the proportion of the variation explained by individual markers. 
the present results with those of others. Based on the approximate chromosomal positions of individual QTL, a number of genomic regions identified in our studies, including chromosomal arms 3BL, 3DS, 4AL, 5DL, and 7DL, could be the same as reported by Kollers et al. (2014), who used 358 European winter wheat accessions. These regions may also correspond to major resistance QTL previously identified in segregating biparental populations (Chu et al. 2008b, Faris and Friesen 2005; Singh et al. 2008; Tadesse et al. 2007). Gurung et al. (2011) identified genomic regions on chromosomes 1D, 2A, 2B, 2D, 4A, and 7D for Pti2 and genomic regions on chromosomes 2D, 6A, and 7D for race 5 in a worldwide spring wheat core collection. We also identified genomic regions on chromosomes 2D and 4A with isolate Pti2 but no common QTL was identified for DW5. There was only one genomic region on 6AL that may be the same between our study and the one done by Patel et al. (2013), who evaluated the worldwide spring wheat core collection with isolate AR CrossB10. The fact that we identified more QTL in common with Kollers et al. (2014) may suggest that genes conditioning resistance to tan spot are different between winter and spring genetic backgrounds. QTL on 5D, 6B, 7A, and 7B have not been reported before. Because the population size used for association mapping was relatively small and the values of $-\log _{10}(P$ value) for the obtained QTL were slightly above 3.0, these new QTL need to be further tested by using a large population or biparental populations. After confirmation, the markers linked to these QTL (Table 4) could be employed to incorporate these resistance genes into HRWW cultivars through marker-assisted selection. It is also possible that these QTL confer sensitivity to uncharacterized NE. If that is the case, the susceptible alleles should be removed to improve resistance in breeding programs.

\section{Acknowledgments}

We thank T. L. Friesen and Z. Zhang for critical review of the manuscript. This material is based upon work supported, in part, by the National Institute of Food and Agriculture, United States Department of Agriculture (USDA), under project number ND02224 to Z. Liu, and by the USDA-NIFA Triticeae Coordinated Agricultural Project, 2011-68002-30029 to P. S. Baenziger, E. Akhunov, and S. Chao. The Triticeae Coordinated Agricultural Project developed and shared the SNP molecular marker information on the lines used in this research.

\section{Literature Cited}

Abeysekara, N. S., Friesen, T. L., Liu, Z. H., McClean, P. E., and Faris, J. D. 2010. Marker development and saturation mapping of the tan spot Ptr ToxB sensitivity locus $T s c 2$ in hexaploid wheat. Plant Genome 3:179-189.

Adhikari, T., Jackson, E. W., Gurung, S., Hansen, J., and Bonman, J. M. 2011. Association mapping of quantitative resistance to Phaeosphaeria nodorum in spring wheat landraces from the USDA national small grains collection. Phytopathology 101:1301-1310.

Alam, K. B., and Gustapson, J. P. 1988. Tan-spot resistance screening of Aegilops species. Plant Breed. 100:112-118.

Ali, S., and Francl, L. J. 2003. Population race structure of Pyrenophora triticirepentis prevalent on wheat and noncereal grasses in the Great Plains. Plant Dis. 87:418-422.

Ali, S., Gurung, S., and Adhikari, T. B. 2010. Identification and characterization of novel isolates of Pyrenophora tritici-repentis from Arkansas. Plant Dis. 94: 229-235.

Ali, S., Singh, P. K., McMullen, M. P., Mergoum, M., and Adhikari, T. B. 2008. Resistance to multiple leaf spotting diseases in wheat germplasm. Euphytica 159:167-179.

Bhathal, J. S., Loughman, R., and Speijers, J. 2003. Yield reduction in wheat in relation to leaf disease from yellow $(\tan )$ spot and septoria nodorum blotch. Eur. J. Plant Pathol. 109:435-443.

Chu, C. G., Friesen, T. L., Faris, J. D., and Xu, S. S. 2008a. Evaluation of seedling resistance to tan spot and Stagonospora nodorum blotch in tetraploid wheat. Crop Sci. 48:1107-1116.

Chu, C. G., Friesen, T. L., Xu, S. S., and Faris, J. D. 2008b. Identification of novel tan spot resistance loci beyond the known host selective toxin insensitivity genes in wheat. Theor. Appl. Genet. 117:873-881.

Chu, C. G., Xu, S. S., Faris, J. D., Nevo, E., and Friesen, T. L. 2008c. Seedling resistance to tan spot and Stagonospora nodorum leaf blotch in wild emmer wheat (Triticum dicoccoides). Plant Dis. 92:1229-1236.

Ciuffetti, L. M., Manning, V. A., Pandelova, I., Betts, M. F., and Martinez, J. P. 2010. Host-selective toxins, Ptr ToxA and Ptr ToxB, as necrotrophic effectors in the Pyrenophora tritici-repentis-wheat interaction. New Phytol. 187:911-919.

De Wolf, E. D., Effertz, R. J., Ali, S., and Francl, L. J. 1998. Vistas of tan spot research. Can. J. Plant Pathol. 20:349-370.

Endelman, J. B. 2011. Ridge regression and other kernels for genomic selection with R package rrBLUP. Plant Genome 4:250-255.
Faris, J. D., and Friesen, T. L. 2005. Identification of quantitative trait loci for racenonspecific resistance to tan spot of wheat. Theor. Appl. Genet. 111:386-392.

Faris, J. D., Liu, Z., and Xu, S. S. 2013. Genetics of tan spot resistance in wheat. Theor. Appl. Genet. 126:2197-2217.

Friesen, T. L., Ali, S., Kianian, S., Francl, L. J., and Rasmussen, J. B. 2003. Role of host sensitivity to Ptr ToxA in development of tan spot wheat. Phytopathology 93:397-401.

Friesen, T. L., Ali, S., Klein, K. K., and Rasmussen, J. B. 2005. Population genetic analysis of a global collection of Pyrenophora tritici-repentis, causal agent of tan spot of wheat. Phytopathology 95:1144-1150.

Friesen, T. L., Chu, C., Xu, S. S., and Faris, J. D. 2012. SnTox5-Snn5: A novel Stagonospora nodorum effector-wheat gene interaction and its relationship with the SnToxA-Tsn1 and SnTox3-Snn3-B1 interactions. Mol. Plant Pathol. 13:1101-1109.

Friesen, T. L., and Faris, J. D. 2010. Characterization of the wheat-Stagonospora nodorum disease system-What is the molecular basis of this quantitative necrotrophic disease interaction. Can. J. Plant Pathol. 32:20-28.

Friesen, T. L., and Faris, J. D. 2012. Characterization of plant-fungal interactions involving necrotrophic effector-producing plant pathogens. Pages 191-207 in: Plant Fungal Pathogens: Methods and Protocols, Methods in Molecular Biology, Vol. 835. M. D. Bolton and B. P. H. J. Thomma, eds. Humana Press, New York.

Friesen, T. L., Meinhardt, S. W., and Faris, J. D. 2007. The Stagonospora nodorum-wheat pathosystem involves multiple proteinaceous host-selective toxins and corresponding host sensitivity genes that interact in an inverse gene-for-gene manner. Plant J. 51:681-692.

Friesen, T. L., Stukenbrock, E. H., Liu, Z., Meinhardt, S. W., Ling, H., Faris, J. D., Rasmussen, J. B., Solomon, P. S., McDonald, B. A., and Oliver, R. P. 2006. Emergence of a new disease as a result of virulence gene transfer. Nat. Genet. 38:953-956.

Friesen, T. L., Zhang, Z. C., Solomon, P. S., Oliver, R. P., and Faris, J. D. 2008. Characterization of the interaction of a novel Stagonospora nodorum hostselective toxin with a wheat susceptibility gene. Plant Physiol. 146:682-693.

Gurung, S., Mamidi, S., Bonman, J. M., Jackson, E. W., del Rio, L. E., Acevedo, M., Mergoum, M., and Adhikari, T. B. 2011. Identification of novel genomic regions associated with resistance to Pyrenophora tritici-repentis races 1 and 5 in spring wheat using association analysis. Theor. Appl. Genet. 123:1029-1041.

Kang, H. M., Zaitlen, N. A., Wade, C. M., Kirby, A., Heckerman, D., Daly, M. J., and Eskin, E. 2008. Efficient control of population structure in model organism association mapping. Genetics 178:1709-23.

Karjalainen, R., Laitinen, A., and Juuti, T. 1983. Effects of Septoria nodorum Berk. on yield and yield components of spring wheat. J. Agric. Sci. Finl. 55:333-344.

King, J. E., Cook, R. J., and Melville, S. C. 1983. A review of Septoria diseases of wheat and barley. Ann. Appl. Biol. 103:345-373.

Kollers, S., Rodemann, B., Ling, J., Korzun, V., Ebmeyer, E., Argillier, O., Hinze, M., Plieske, J., Kulosa, D., Ganal, M. W., and Röder, M. S. 2014. Genome-wide association mapping of tan spot resistance (Pyrenophora tritici-repentis) in European winter wheat. Mol. Breed. 34:363-371

Lamari, L., and Bernier, C. C. 1989. Evaluation of wheat lines and cultivars to tan spot [Pyrenophora tritici-repentis] based on lesion type. Can. J. Plant Pathol. 11:49-56.

Liu, Z. H., Faris, J. D., Meinhardt, S. W., Ali, S., Rasmussen, J. B., and Friesen, T. L. 2004a. Genetic and physical mapping of a gene conditioning sensitivity in wheat to a partially purified host-selective toxin produced by Stagonospora nodorum. Phytopathology 94:1056-1060.

Liu, Z. H., Faris, J. D., Oliver, R. P., Tan, K., Solomon, P. S., McDonald, M. C. McDonald, B. A., Nunez, A., Lu, S., Rasmussen, J. B., and Friesen, T. L. 2009. SnTox3 acts in effector triggered susceptibility to induce disease on wheat carrying the Snn3 gene. PLoS Pathog. 5:1-15.

Liu, Z. H., Friesen, T. L., Rasmussen, J. B., Ali, S., Meinhardt, S. W., and Faris, J. D. 2004b. Quantitative trait loci analysis and mapping of seedling resistance to Stagonospora nodorum leaf blotch in wheat. Phytopathology 94:1061-1067.

Liu, Z. H., Zhang, Z., Faris, J. D., Oliver, R. P., Syme, R., McDonald, M. C., McDonald, B. A., Solomon, P. S., Lu, S., Shelver, W. L., Xu, S. S., and Friesen, T. L. 2012. The cysteine rich necrotrophic effector SnTox1 produced by Stagonospora nodorum triggers susceptibility of wheat lines harboring Snn1. PLoS Pathog. 8:e1002467.

McMullen, M., and Adhikari, T. B. 2009. Fungal leaf spot diseases of wheat: Tan spot, Stagonospora nodorum blotch and Septoria tritici blotch. Plant Dis. Manage. NDSU Ext. Serv. PP-1249 (revised). Online publication. https://www.ag.ndsu. edu/pubs/plantsci/pests/pp1249.pdf

Mergoum, M., Singh, P. K., Ali, S., Elias, E. M., Anderson, J. A., Glover, K. D., and Adhikari, T. B. 2007. Reaction of elite wheat genotypes from the northern Great Plains of North America to Septoria diseases. Plant Dis. 91:1310-1315.

Noriel, A. J., Sun, X. C., Bockus, W., and Bai, G. 2011. Resistance to tan spot and insensitivity to Ptr ToxA in wheat. Crop Sci. 51:1059-1067.

Oliver, R. E., Cai, X., Wang, R. C., Xu, S. S., and Friesen, T. L. 2008. Resistance to tan spot and Stagonospora nodorum blotch in wheat-alien species derivatives. Plant Dis. 92:150-157.

Oliver, R. P., Friesen, T. L., Faris, J. D., and Solomon, P. S. 2012. Stagonospora nodorum: From pathology to genomics and host resistance. Annu. Rev. Phytopathol. 50:23-43.

Patel, J. S., Mamidi, S., Bonman, J. M., and Adhikari, T. B. 2013. Identification of QTL in spring wheat associated with resistance to a novel isolate of Pyrenophora tritici-repentis. Crop Sci. 53:842-852. 
Ransom, J., Marais, F., Riopel, J., Lukach, J., Martin, G., Penuel, C., Amiot, C., Ostlie, M., and Markell, S. 2013. North Dakota hard winter wheat: Variety trial results for 2013 and selection guide. NDSU Ext. Serv. A1196-13. Online publication. https://www.ag.ndsu.edu/pubs/plantsci/smgrains/ a1196_13.pdf

Rees, R. G., and Platz, G. J. 1990. Sources of resistance to Pyrenophora triticirepentis in bread wheats. Euphytica 45:59-69.

SAS Institute. 2010. SAS/STAT User's Guide, Rel. 8.2, 8.1, 8.0. SAS Institute, Cary, NC.

Schilder, A. M. C., and Bergstrom, G. C. 1990. Variation in virulence within the population of Pyrenophora tritici-repentis in New York. Phytopathology 80:84-90.

Shabeer, A., and Bockus, W. W. 1988. Tan spot effects on yield and yield components relative to growth stage in winter wheat. Plant Dis. 72: 599-602.

Singh, P. K., Mergoum, M., Ali, S., Adhikari, T. B., Elias, E. M., Anderson, J. A., Glover, K. D., and Berzonsky, W. A. 2006. Evaluation of elite wheat germ plasm for resistance to tan spot. Plant Dis. 90:1320-1325.

Singh, P. K., Mergoum, M., Ali, S., Adhikari, T. B., and Hughes, G. R. 2008. Genetic analysis of resistance to Pyrenophora tritici-repentis races 1 and 5 in tetraploid and hexaploid wheat. Phytopathology 98:702-708.

Tadesse, W., Schmolke, M., Hsam, S. L. K., Mohler, V., Wenzel, G., and Zeller, F. J. 2007. Molecular mapping of resistance genes to tan spot [Pyrenophora triticirepentis race 1] in synthetic wheat lines. Theor. Appl. Genet. 114:855-862.
Tommasini, L., Schnurbusch, T., Fossati, D., Mascher, F., and Keller, B. 2007. Association mapping of Stagonospora nodorum blotch resistance in modern European winter wheat varieties. Theor. Appl. Genet. 115:697-708.

Wang, S., Wong, D., Forrest, K., Allen, A., Chao, S., Huang, B. E., Maccaferri, M. Salvi, S., Milner, S. G., Cattivelli, L., Mastrangelo, A. M., Whan, A., Stephen, S., Barker, G., Wieseke, R., and Plieske, J., International Wheat Genome Sequencing Consortium. Lillemo, M., Mather, D., Appels, R., Dolferus, R., Brown-Guedira, G., Korol, A., Akhunova, A. R., Feuillet, C., Salse, J., Morgante, M., Pozniak, C., Luo, M., Dvorak, J., Morell, M., Dubcovsky, J., Ganal, M., Tuberosa, R., Lawley, C., Mikoulitch, I., Cavanagh, C., Edwards, K. J., Hayden, M., and Akhunov, E. 2014. Characterization of polyploid wheat genomic diversity using a high-density 90000 single nucleotide polymorphism array. Plant Biotechnol. J. 12:787-796.

Xu, S. S., Friesen, T. L., and Cai, X. 2004a. Sources and genetic control of resistance to Stagonospora nodorum blotch in wheat. Pages 449-469 in: Recent Research Development in Genetics and Plant Breeding, Vol. 1, Part II. S. G. Pandalai, ed. CAB Direct, Research Signpost, Kerala, India.

Xu, S. S., Friesen, T. L., and Mujeeb-Kazi, A. 2004b. Seedling resistance to tan spot and Stagonospora nodorum blotch in synthetic hexaploid wheats. Crop Sci. 44:2238-2245

Zhang, Z., Friesen, T. L., Xu, S. S., Shi, G., Liu, Z., Rasmussen, J. B., and Faris, J. D. 2011. Two putatively homoeologous wheat genes mediate recognition of SnTox3 to confer effector-triggered susceptibility to Stagonospora nodorum. Plant J. 65:27-38. 